International Journal of

Emerging Multidisciplinary Research

\title{
Research on Online Reviews Diagnosis' Effects on Perceptual Information Symmetry
}

\author{
PengFei Qin ${ }^{1}$, JinDan lyu ${ }^{2}$, Yi Zhao ${ }^{3 *}$ \\ ${ }^{1,2,3}$ Department of MIS, Chungbuk National University, Chungbuk, 28644, South Korea
}

\begin{abstract}
Background/Objectives: In this thesis, an empirical study was conducted on consumers' diagnosis on online reviews in the process of purchasing. Methods/Statistical analysis: In order to verify the viewpoint of this research, this study chooses consumers who have the experience of searching online reviews as the research object, collects data based on a questionnaire from 64 men and 61 women and uses Smart PLS to verify the structural model. Findings: The results of this research are as follows: first, the review diagnosticity sufficiency has positive (+) effects on perceptual information symmetry. Second, the diagnosis on positive online reviews has positive (+) effects on perceptual information symmetry. Third, the diagnosis on negative online reviews has positive $(+)$ effects on perceptual information symmetry. Improvements/Applications: The implications of this study are verifies the effects of the diagnosis of commodities' online reviews, diagnosis of positive and negative online reviews on consumers' perceptual information symmetry.
\end{abstract}

\section{Index Terms}

Review diagnosticity sufficiency, Diagnosis on positive online reviews, Diagnosis on negative online reviews, Perceptual information symmetry

\section{Corresponding author : Yi Zhao \\ zhaoyi207@gmail.com \\ - Manuscript received April 4, 2021. \\ - Revised April 25, 2021; Accepted May 9, 2021. \\ - Date of publication June 30, 2021.}

(C) The Academic Society of Convergence Science Inc.

2546-1583 @ 2017 IJEMR. Personal use is permitted, but republication/redistribution requires IJEMR permission. 


\section{INTRODUCTION}

Online reviews of commodities are a manifestation of information symmetry and the disappearance of information monopoly[1].

Online reviews can solve some problems caused by information asymmetry. Examples of these problems include: the aggravation of uncertainty, the deterioration of the trust relationship between the buyer and the seller and the avoidance of buying and the buying of inferior goods [2, 3]. Moreover, problems even include the fairness of the commodity market and its reduced efficiency [4].

The current studies focus on research on how excessive reviews, favorable and unfavorable may cause information asymmetry[5-7]. This study consulted the Accessibility - Dignosticity Model which contends that in order to reduce the risk of purchasing, consumers search for information from their individual memories for the purpose of comparing information[8].

When consumers diagnose the online reviews of commodities, they compare information from their memories based on features such as positiveness and negativeness of information[9]. In this study, the process of comparing the commodity's online reviews and the information of the commodity from the consumer's memory is referred to as the diagnosis of online reviews. The perceptual information symmetry forms when the results of diagnosis are similar.

This study contends that consumers will sufficiently compare the commodity's online reviews and the information of the commodity from the consumer's memory. It contends that the more the content of online reviews accords with the content of the consumer's memory, the more symmetrical the perceptual information is $[10,11]$.

Generally, positive online reviews form a trust relationship between the buyer and the seller when the former makes diagnosis of positive reviews, and the symmetry of perceptual information improves as a result $[12,13]$.

However, when the consumer makes diagnosis on negative online reviews, he/she makes comparisons between the negative review and negative memories about the commodity from his/her memories to ensure that the commodity is worth buying and to avoid risks and the consequential negative emotions.

The more such negative online reviews accord with the content of the consumer's memory, the more symmetrical the perceptual information is[1415].

\section{Current Studies}

\section{A. Review diagnosticity sufficiency}

The sufficiency of information, also known as the sufficiency of information transmission, is determined based on the amount of the information[17]. In the process of online shopping, consumers need to engage in information search and information acquisition about the commodity that they desire[18, 19].

The larger the quality of the commodity's online reviews, the more likely the consumers regard these reviews as dependable[20]. Meanwhile, the larger the quality of the diagnoses on the online reviews, the more positive their attitude is toward the commodity[21].

Also, more online reviews means that there are more indirect experiences with using the commodity[22] and that there is a lower perceptual risk and perceptual uncertainty[23, 24]. When consumers collect a sufficient amount of information to meet their needs and expectations, their perception level of the information quality improves[25-28].

\section{B. Diagnosis on positive online reviews}

Diagnosis on positive online reviews refers to the consumer's diagnosis of positive reviews that reflect the quality of the commodity[29, 30].

Consumers tend to store the positive information about the commodity in their memories, and the purpose of the diagnosis on positive online reviews is that when the consumer decides whether to buy the commodity, he/she extracts the positive information from his/her memory and makes comparisons and diagnoses with the commodity's reviews[31].

People tend to present a friendly attitude toward the target object in a positive information framework, and therefore increase their intention to accept positive reviews[32]. Generally, the positive reviews that the consumer diagnoses are very similar to the positive information about the commodity in his/her individual memory.

The positive reviews and positive information in the consumer's memory are related on a certain level[33-36]. In the meantime, some people tend to pay attention to the stimulation of positive words in information processing.

This phenomenon is referred to as an inclination for positive clues, which leads the consumer to extract positive information from his/her memory for reference[37, 38]. The interactions between positive reviews and the consumer's memory play a crucial role in the consumer's purchasing behavior, decision-making and satisfaction[39-41]. 


\section{Diagnosis on negative online reviews}

Diagnosis on negative online reviews refers to the consumer's diagnosis of negative reviews that reflect the quality of the commodity[42].

Consumers tend to store the negative information about the commodity in their memories. The purpose of the diagnosis on negative online reviews is that when the consumer decides whether to buy the commodity, he/she extracts the negative information from his/her memory and makes comparisons and diagnoses with the commodity's reviews[31].

According to the social information processing model, in information processing, consumers compare the tacit knowledge structure that they have obtained from past experiences and memories with the current information.

If the previous memory structure is negative, the consumer is then more likely to give negative explanations for the current clues and accept negative solutions[43]. This is because in a negative information framework, the intention to make diagnoses of negative information becomes stronger in order to avoid potential risks [44].

In the meantime, in information processing, some people have an inclination to be stimulated by negative words. This phenomenon is referred to as an inclination for negative clues[38], which consistently affects the individual's judgement[45].

In a word, consumers can make diagnoses of the commodity's quality based on negative information to improve their perception of the commodity and prevent unsatisfactory or negative result [9, 46-48 ].

\section{Perceptual information symmetry}

Information symmetry is a concept that describes the amount of information about y string included in $\mathrm{x}$ string, which also means that $\mathrm{x}$ string and $\mathrm{y}$ string are almost identical.

Information symmetry means that there is no difference among the information possessed by individual market participants, and that there is no information gap among the economic subjects[49].

Information symmetry means there is an absence of information gap between the seller and the buyer, it also makes it easy for members of the society to share and obtain the information they have [1].

Through the Internet, consumers today are able to acquire information close to their thoughts and emotions and spread such thoughts and emotions to others[1, 50,51].

This kind of information symmetry prevents information on the Internet to be monopolized by a certain stratum and selectively processed and transmitted to a specific target stratum[1, 52, 53].
In this study, the consumer's perception in the purchasing process that there is no difference between the commodity's reviews and the past known information is referred to as perceptual information symmetry.

\section{Research Models and Hypotheses}

\section{A. Research Model}

In ADM(Accessibility-Dignosticity Model)theory, accessibility refers to the amount of information extracted from the individual's memory. Diagnosticity means to solve current issues with the information extracted from the memory [8].

When consumers make a purchase decision, they tend to extract a certain amount of information related to the commodity from their memory and compare it with the commodity's reviews according to the direction of the information[54].

The information stored in the individual's memory will be reflected after the consumer makes a certain quantity of analyses of others' comments[9]. The reviews can be divided into two directions: positive and negative; when the consumer diagnoses positive reviews, this triggers his/her actions leaning to the positive reviews[55].

When the consumer comes into contact with negative reviews, he/she will have an intention of avoiding purchase risks[14] and extract information about failed purchases to prevent negative purchase results $[15,16]$.

According to the theoretical background above, this research sets the following research model (see Figure 1):

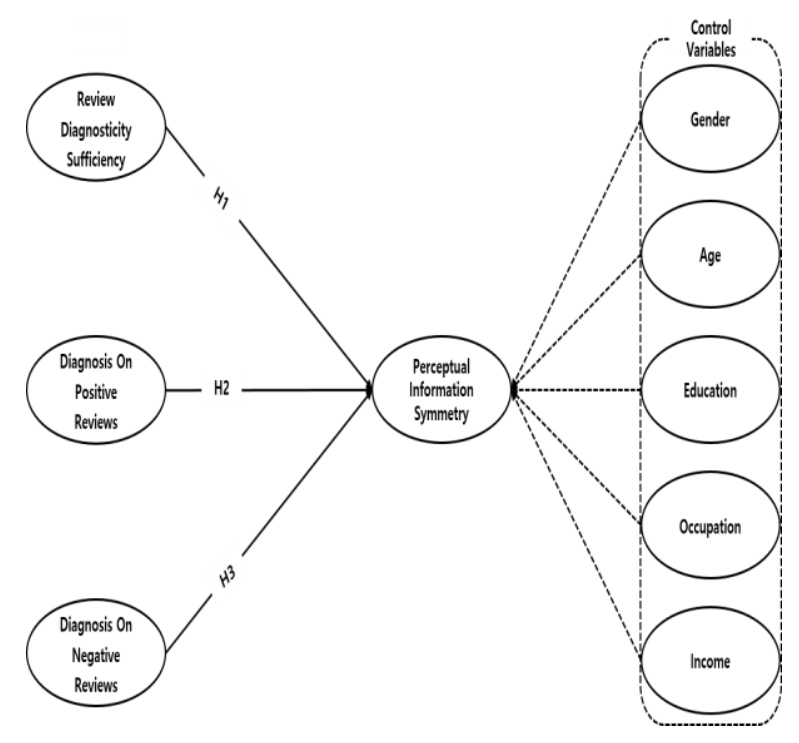

Fig. 1. Research Model 


\section{B. The Relation between review diagnosticity sufficiency and perceptual information symmetry.}

Review diagnosticity sufficiency refers to diagnosis on positive online reviews refers to the consumer's adequately quantitative diagnosis of the commodity's reviews in the process of online shopping[20, 56].

The consumer can understand the commodity and reduce the risk of purchasing by adequately processing information of the commodity $[9,17]$.

Review diagnosticity sufficiency means that reviews diagnosed by consumers evoke a certain amount of information stored in the individual's memory which is related to the commodity's functions, size, etc[54 57, 58].

In the large amount of information diagnosed by the consumer, the more the relative information that the consumer stores in his/her individual memory, the stronger the individual's perceptual information symmetry[49, 9]. From the perspective of social impact, the consumer compares his/her experience with that of others[58].

Therefore, the more such negative online reviews accord with the consumer's memory, the more symmetrical the perceptual information is $[9,60]$.

Hypothesis 1: Review diagnosticity sufficiency has positive (+) effects on perceptual information symmetry.

\section{The Relation between diagnosis on positive online reviews and perceptual Information symmetry}

Diagnosis on positive online reviews refers to the act of consumers to read and understand the commodity's positive reviews when processing the information about the commodity[29, 30].

Diagnosis on positive online reviews means that the consumer assumes the positive reviews are dependable information[33]. Positive reviews construct the trust-relationship between the provider and the demander of the commodity's information, and increase perceptual information symmetry[12, 13].

Diagnosis on positive online reviews leads consumers to have a positive attitude toward the commodity[61], and stimulates the consumers to perform positive actions[55].

Thereby, the consumer's perceptual information symmetry is improved[62, 63]. Hence, this study contends that diagnosis on positive online reviews increases perceptual information symmetry.

\section{Hypothesis 2: Diagnosis on positive online}

reviews has positive (+) effects on perceptual information symmetry.

Table 1. QuestionnAire

\begin{tabular}{|c|c|c|}
\hline Construct & Content & Provenance \\
\hline \multirow{4}{*}{$\begin{array}{l}\text { Review } \\
\text { Diagnosticity } \\
\text { Sufficiency }\end{array}$} & $\begin{array}{l}\text { The product I bought seems to } \\
\text { have enough reviews. }\end{array}$ & \multirow{4}{*}{ [20] } \\
\hline & $\begin{array}{l}\text { There seems to be a lot of } \\
\text { reviews from many people who } \\
\text { bought the product. }\end{array}$ & \\
\hline & $\begin{array}{l}\text { There seem to be many reviews } \\
\text { detailed. }\end{array}$ & \\
\hline & $\begin{array}{l}\text { I think there are more reviews } \\
\text { than other shopping malls. }\end{array}$ & \\
\hline \multirow{4}{*}{$\begin{array}{l}\text { Diagnosis } \\
\text { On Positive } \\
\text { Online } \\
\text { Reviews }\end{array}$} & $\begin{array}{l}\text { I tend to look at positive reviews } \\
\text { to find out the price of the } \\
\text { product. }\end{array}$ & \multirow{8}{*}{ [22] } \\
\hline & $\begin{array}{l}\text { I tend to look at positive reviews } \\
\text { to check the delivery of products. }\end{array}$ & \\
\hline & $\begin{array}{l}\text { I tend to look at positive reviews } \\
\text { to find out the after-sales service } \\
\text { of the product. }\end{array}$ & \\
\hline & $\begin{array}{l}\text { I tend to look at positive reviews } \\
\text { to see the seller's attitude. }\end{array}$ & \\
\hline \multirow{4}{*}{$\begin{array}{l}\text { Diagnosis } \\
\text { On Negative } \\
\text { Online } \\
\text { Reviews }\end{array}$} & $\begin{array}{l}\text { I tend to look at positive reviews } \\
\text { to find out the price of the } \\
\text { product. }\end{array}$ & \\
\hline & $\begin{array}{l}\text { I tend to look at positive reviews } \\
\text { to check the delivery of products. }\end{array}$ & \\
\hline & $\begin{array}{l}\text { I tend to look at positive reviews } \\
\text { to find out the after-sales service } \\
\text { of the product. }\end{array}$ & \\
\hline & $\begin{array}{l}\text { I tend to look at positive reviews } \\
\text { to see the seller's attitude. }\end{array}$ & \\
\hline \multirow{3}{*}{$\begin{array}{l}\text { Perceptual } \\
\text { Information } \\
\text { Symmetry }\end{array}$} & $\begin{array}{l}\text { After reading the reviews, I } \\
\text { thought the product matched the } \\
\text { information provided by the } \\
\text { seller. }\end{array}$ & \multirow{3}{*}{ [49] } \\
\hline & $\begin{array}{l}\text { After reading the reviews, I } \\
\text { thought it was similar to the } \\
\text { information I knew. }\end{array}$ & \\
\hline & $\begin{array}{l}\text { After reading the reviews, I } \\
\text { thought the product matched the } \\
\text { information provided by the } \\
\text { seller. }\end{array}$ & \\
\hline
\end{tabular}

\section{The Relation between diagnosis on negative online reviews and perceptual information Symmetry}

Diagnosis on negative online reviews is the act of consumers to read and understand the commodity's negative reviews when processing the information about the commodity[29, 30]. Diagnosis on negative online reviews prevents the result of the consumer failing to purchase[64, 14].

Hence, Diagnosis on negative online reviews means that the consumer extracts information about similar failure(s) of purchase and makes comparisons.

This kind of comparisons based on the negativity of information improves the consumer's perception of information symmetry[9, 15, 16, 65]. 
Therefore, this study contends that diagnosis on negative online reviews increases perceptual information symmetry.

Hypothesis 3: Diagnosis on negative online reviews has positive (+) effects on perceptual information symmetry.

\section{E. Control Variables}

Back to the regression analysis, in the research of SEM(Structural Equation Modeling), if only the causal relationship is analyzed statistically and the control of exogenous variable is not considered, the inferential results between related variables will be wrong. Demographical variables such as gender, age, education level is usually used as the control variable.

Therefore, this study adds variables including gender, age, income and education level on the basis of hypothesis.

\section{RESEARCH METHODOLOGY AND ANALYSIS RESULTS}

\section{A. Research data and analysis methods}

As presented in <Table 1>, this questionnaire was modified based on the previous research to make it consistent with this study. 18 questions in the questionnaire were measured with the Likert scale.

As <Table 2> shows, the respondents of this study are Korean consumers who have experiences of diagnosing online reviews. In this study, 124 valid data were collected for data analysis.

\section{B. Analysis Tools}

This research uses Smart-PLS 2.0 to determine the effects of review diagnosticity sufficiency, Diagnosis on positive online reviews and diagnosis on negative online reviews on perceptual information symmetry.

The advantage of Smart-PLS 2.0 is that in the process of model inference, it minimizes residual error, minimize the residual error and maximize the predicted value of the coefficient, especially with the inferred model based on the principal component [66].

Smart-PLS 2.0 also applies to analysis of formative and reflective index[67-69]. Additionally, Smart-PLS 2.0 can be used for analysis even when the sample size is relatively small[70-71].

\section{Analysis of Reliability \& Validity}

This study uses PLS to analyze Convergent validity, Discriminant validity and Internal consistency of each construct. The analysis results are presented in $<$ Table 3>.

Table 2. DEMOGRAPHICS

\begin{tabular}{|c|c|c|c|}
\hline $\begin{array}{l}\text { Nominal } \\
\text { Variables }\end{array}$ & category & Frequency & $\%$ \\
\hline \multirow{4}{*}{ Age } & teenager & 2 & 1.6 \\
\hline & $20 \mathrm{~s}$ & 97 & 77.6 \\
\hline & $30 \mathrm{~s}$ & 14 & 11.2 \\
\hline & $40 \mathrm{~s}$ & 12 & 9.6 \\
\hline \multirow{5}{*}{$\begin{array}{l}\text { Intended } \\
\text { Degree }\end{array}$} & Three-year college & 8 & 6.4 \\
\hline & 4-year undergraduate & 80 & 64 \\
\hline & 4-year bachelor degree & 14 & 11.2 \\
\hline & Graduate student & 11 & 8.8 \\
\hline & Master graduate & 12 & 9.6 \\
\hline \multirow{5}{*}{ Profession } & Staff & 12 & 9.6 \\
\hline & private & 3 & 2.4 \\
\hline & housewife & 2 & 1.6 \\
\hline & student & 97 & 77.6 \\
\hline & other & 11 & 8.8 \\
\hline \multirow{5}{*}{$\begin{array}{l}\text { Frequency } \\
\text { of online } \\
\text { shopping }\end{array}$} & 12 times & 51 & 40.8 \\
\hline & 3- 5 times & 40 & 32 \\
\hline & 6-10 times & 25 & 20 \\
\hline & 11-20 times & 6 & 4.8 \\
\hline & More than 21 times & 3 & 2.4 \\
\hline
\end{tabular}

\begin{tabular}{|c|c|c|c|}
\hline $\begin{array}{l}\text { Nominal } \\
\text { Variables }\end{array}$ & category & Frequency & $\%$ \\
\hline \multirow{2}{*}{ Gender } & male & 64 & 51.2 \\
\hline & Female & 61 & 48.8 \\
\hline \multirow{7}{*}{$\begin{array}{l}\text { Monthly } \\
\text { Income }\end{array}$} & Below 1800 yuan & 27 & 21.6 \\
\hline & 1800 yuan-3000 yuan & 44 & 35.2 \\
\hline & 3000 yuan- 6000 yuan & 21 & 16.8 \\
\hline & 6000 yuan- 9000 yuan & 7 & 5.6 \\
\hline & 9000 yuan -12000 yuan & 7 & 5.6 \\
\hline & 12,000 yuan- 18,000 yuan & 10 & 8 \\
\hline & 18,000 yuan or more & 9 & 7.2 \\
\hline \multirow{10}{*}{$\begin{array}{l}\text { Price of the } \\
\text { goods } \\
\text { purchased }\end{array}$} & Less than 300 yuan & 20 & 16 \\
\hline & 300 yuan to 600 yuan & 8 & 6.4 \\
\hline & 600 yuan $\sim 1200$ yuan & 17 & 13.6 \\
\hline & 1200 yuan $\sim 1800$ yuan & 10 & 8 \\
\hline & 1800 yuan $\sim 2400$ yuan & 28 & 22.4 \\
\hline & RMB 2400 3000 & 2 & 1.6 \\
\hline & 3000 yuan $\sim 3600$ yuan & 0 & 0 \\
\hline & 3600 yuan or more & 40 & 32 \\
\hline & 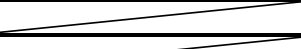 & 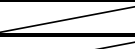 & \\
\hline & & 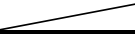 & 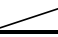 \\
\hline
\end{tabular}

The result shows that AVE value is 0.5 above the standard, indicating that this study has Convergent validity[68]. Composite Reliability is 0.8 above the standard, and Cronbachs $\alpha$ is 0.7 above the standard, which verifies that this research model has appropriate Internal consistency [72]).

According to $\langle$ Table 3$\rangle$, the minimum value of the square root of AVE value of each variable is 
0.736, higher than the maximum correlation coefficient of 0.436 . This verifies that this research model has discriminant validity[73].

\section{Confirmatory Factor Analysis}

In the process of analyzing the validity of the model, Confirmatory Factor Analysis needs to be conducted. Confirmatory Factor Analysis refers to whether the value of Cross-factor loading to verify
Construct reaches $0.5[66]$. As presented in <Table $4>$, every Cross-factor loading of Construct in this research is above 0.6. In the general field of social science, the extracted factors have $60 \%$ of explanatory power to variables, which proves that the correlation between factors and variables is very high.

Table 3. Reliability \& Validity Analysis

\begin{tabular}{c|c|c|c|c|c|c|c}
\hline Construct & AVE & CR & Cronbachs $\alpha$ & 1 & 2 & 3 & 4 \\
\hline $\begin{array}{c}\text { 1. Diagnosis On Positive } \\
\text { Online Reviews }\end{array}$ & 0.544 & 0.825 & 0.74 & 0.738 & & & \\
\hline $\begin{array}{c}\text { 2. Diagnosis On Negative } \\
\text { Online Reviews }\end{array}$ & 0.541 & 0.822 & 0.716 & 0.436 & 0.736 & & \\
\hline $\begin{array}{c}\text { 3. Perceptual Information } \\
\text { Symmetry }\end{array}$ & 0.651 & 0.846 & 0.72 & 0.352 & 0.333 & 0.807 & \\
\hline $\begin{array}{c}\text { 4. Review Diagnosticity } \\
\text { Sufficiency }\end{array}$ & 0.659 & 0.885 & 0.838 & 0.112 & 0.113 & 0.294 & 0.812 \\
\hline
\end{tabular}

Table 4. CONFIRMATORY FACTOR ANALysis

\begin{tabular}{|c|c|c|c|c|}
\hline Construct & $\begin{array}{l}\text { Review Diagnosticity } \\
\text { Sufficiency }\end{array}$ & $\begin{array}{c}\text { Diagnosis On } \\
\text { Positive Online } \\
\text { Reviews } \\
\end{array}$ & $\begin{array}{c}\text { Diagnosis On } \\
\text { Negative Online } \\
\text { Reviews } \\
\end{array}$ & $\begin{array}{c}\text { Perceptual } \\
\text { Information Symmetry }\end{array}$ \\
\hline \multirow{4}{*}{$\begin{array}{l}\text { Review Diagnosticity } \\
\text { Sufficiency }\end{array}$} & 0.835 & 0.001 & -0.012 & 0.212 \\
\hline & 0.761 & -0.010 & -0.018 & 0.102 \\
\hline & 0.798 & 0.178 & 0.186 & 0.250 \\
\hline & 0.851 & 0.116 & 0.126 & 0.303 \\
\hline \multirow{4}{*}{$\begin{array}{l}\text { Diagnosis On Positive } \\
\text { Online Reviews }\end{array}$} & 0.138 & 0.782 & 0.305 & 0.343 \\
\hline & 0.076 & 0.606 & 0.204 & 0.097 \\
\hline & 0.052 & 0.745 & 0.408 & 0.238 \\
\hline & 0.045 & 0.802 & 0.342 & 0.258 \\
\hline \multirow{4}{*}{$\begin{array}{l}\text { Diagnosis On Negative } \\
\text { Online Reviews }\end{array}$} & 0.133 & 0.392 & 0.608 & 0.192 \\
\hline & 0.185 & 0.177 & 0.630 & 0.156 \\
\hline & 0.051 & 0.369 & 0.881 & 0.341 \\
\hline & 0.032 & 0.326 & 0.788 & 0.237 \\
\hline \multirow{3}{*}{$\begin{array}{l}\text { Perceptual Information } \\
\text { Symmetry }\end{array}$} & 0.253 & 0.323 & 0.226 & 0.870 \\
\hline & 0.280 & 0.280 & 0.274 & 0.882 \\
\hline & 0.171 & 0.244 & 0.307 & 0.649 \\
\hline
\end{tabular}

\section{E. Result}

In this study, the $\mathrm{R}^{2}$ of all endogenous variables in the structural model is 0.24 . To prove the adaptability of the model, the study calculated its Goodness of Fit has three levels: up (above 0.26), middle (above 0.13) and down (0.02). Using the formula, the GOF is calculated as 0.417 , which indicates that this research model has a high adaptability[71].

As shown in <Figure 2>, the following can be concluded from the analysis results of this study:

Hypothesis 1: Review diagnosticity sufficiency has positive $(+)$ effects on perceptual information symmetry. $(\beta=0.245, \mathrm{p}<0.01)$ Established.
Hypothesis 2: Diagnosis on positive online reviews has positive (+) effects on perceptual information symmetry. $(\beta=0.212, \quad \mathrm{p}<0.01)$ Established.

Hypothesis 3: Diagnosis on negative online reviews has positive (+) effects on perceptual information symmetry. $(\beta=0.192, \quad \mathrm{p}<0.01)$ Established.

\section{F. Discussion OF Hypothesis 1: Review diagnosticity sufficiency has positive (+) effects on perceptual information symmetry.}

This study verifies that consumers' Review diagnosticity sufficiency has positive effects on 
perceptual information symmetry. The content of hypothesis 1 is the same as the research result that the increase of information will affect perceptual information symmetry[60].

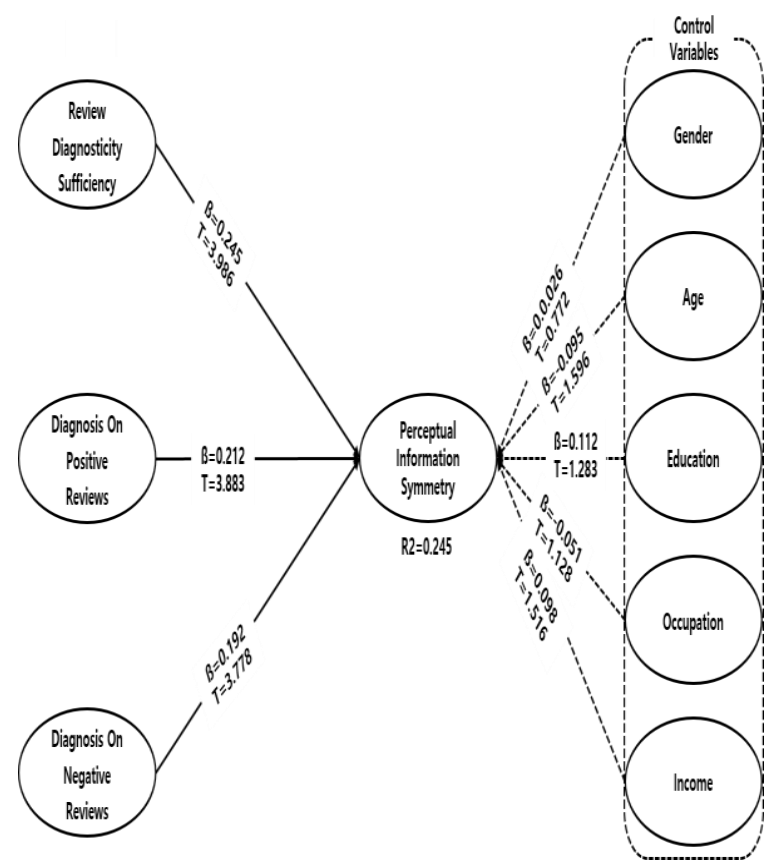

Fig. 2. Model Analysis Results

Members of society compare the information they have, so the consumer will sufficiently make quantized diagnosis of reviews posted by others. The more relative reviews that the consumer has in his/her individual memory, the stronger the perceptual information symmetry.

In the meantime, this proves the importance of the quantity of reviews; administrators need develop a strategic plan to encourage consumers to write reviews to increase the number of online reviews, so as to improve consumers' awareness of the commodity.

\section{G. Discussion OF Hypothesis 2: Diagnosis on positive online reviews has positive $(+)$ effects on perceptual information symmetry.}

This study validates that diagnosis on positive online reviews has positive effects on perceptual information symmetry. This result is consistent with the research result that consumer will have positive emotions in a positive atmosphere[55].

This means that the consumer forms a trustrelationship with the reviewer through Diagnosis on positive online reviews, and extracts information similar to the positive reviews being diagnosed at the moment from his/her memory.
Thereby, it is necessary for administrators to urge the development of a system that refines positive reviews of goods according to different attributes to improve the convenience of consumer diagnosis, reduce the time cost of consumers and improve the efficiency of shopping.

\section{H. Discussion OF Hypothesis 3: Diagnosis on negative online reviews has positive (+) effects on perceptual information symmetry.}

This study verifies that diagnosis on negative online reviews has positive effects on perceptual information symmetry. This result is consistent with the previous research on negative emotions induced by consumers' negative comments on commodity attributes[45].

This means that negative comment diagnosis leads to consumers' intention to avoid purchase risks and extract negative knowledge close to the current negative reviews from personal shopping experiences.

Therefore, it is necessary for the administrators to collect and analyze the negative comments uploaded by the buyers, build the knowledge reserve management system of commodity defects, and formulate the scheme to improve the defects.

\section{Conclusion}

In this research, Korean consumers with experiences of online searches and reviews were selected as the respondents to verify the relationship between consumers' diagnosis of reviews and the perceptual information symmetry.

The research results are as follows: first, this research verifies the positive effect that review diagnosticity sufficiency has on perceptual information symmetry. Review diagnosticity sufficiency urges the consumer to extract relevant amount of commodity information from their personal memory.

The more relative reviews that the consumer has in memory, the stronger the perceptual information symmetry. Second, this research verifies the positive effect that diagnosis on positive online reviews has on perceptual information symmetry.

Diagnosis on positive online reviews leads the consumer to have positive emotions and make positive actions toward the positive reviews in a positive atmosphere, and urges the consumer to extract information similar to the positive reviews being diagnosed at the moment from his/her memory.

Third, this research verifies the positive effect that diagnosis on negative online reviews has on perceptual information symmetry. Diagnosis on 
negative online reviews makes consumers extract negative knowledge close to the current negative reviews from personal shopping experiences to avoid purchase risks.

According to the results of this study, the following academic implications are proposed:

Many previous studies propose the information asymmetry between buyers and sellers. In contrast, based on the diagnostic behavior of social members sharing information in similar and different directions, this study verifies the inference that consumers' personal perceptual information symmetry is improved by sufficiently diagnosing the reviews and diagnosing the reviews from both the positive and negative directions.

These results provide a theoretical basis for the research of consumer's behavior and psychology. Meanwhile, from the perspective of consumers' purchasing process, the information symmetry achieved by consumers' diagnosis of reviews has enlightening significance for the research direction of the purchase decision, reliability, and even satisfaction after the purchase.

This research verifies that consumers' review diagnosticity sufficiency, Diagnosis on positive online reviews and diagnosis on negative online reviews are helpful for improving perceptual information symmetry. This means that product reviews can improve the information transparency between buyers and sellers.

Therefore, from the perspective of the developers of online shopping systems, product reviews can be subdivided into internal and external, positive and negative based on their attributes in order to improve the convenience of consumer shopping, save information search time, reduce purchase risks and the switching cost.

It is necessary to subdivide the causes of consumers' purchase failures especially in the process of developing the function of subdividing negative reviews.

Such subdivision helps consumers make more secure purchase decisions and improve the success rate of purchase. This research provides an empirical basis for the above suggestions.

\section{REFERENCES}

[1] Park, Joon Hyoung, Kim., \& Bong Hyun. (2015). A Study of The New IMC Concept Required in the Social Media Environment. The Korean Journal of Advertising and Public Relations, 17(1), 193-234.

[2] Kim Hyung Joon., \& Kim Yong Il. (2014). The Influence of Building Trust by Characteristics of e-WOM Based on Application of Food Information Service on Behavior Intention. Korean Journal of Hospitality \& Tourism, 23(1), 45-64.
[3] Kim Jong Hwa. (2014). A Study on the Mechanism of Asymmetric Quality Information in Fresh Food Internet Transaction, Korea National Sport Univ, 5, 1-22.

[4] Lee Soo-Hyung, Moon Sun-Jung, Song Jong-Ho., \& An SoYoung. (2013). The Effect of Extrinsic Cues on Consumer's Evaluation and Purchase Intention of Eco-friendly Product Focusing on Dishwashing Detergent's Eco-mark. Korean Journal of Environmental Education, 26(1), 128-143.

[5] Keil, M., Smith, H. J., Pawlowski, S., \& Jin, L. (2004). Why didn't somebody tell me?': climate, information asymmetry, and bad news about troubled projects. ACM SIGMIS Database: the DATABASE for Advances in Information Systems, 35(2), 65-84.

[6] Cho Joong-Seok., \& Jo Mun-Hee. (2007). The Relation between Information Asymmetry and the Cost of Capital. Korean Association for Accounting and Policy, 12(2). 269288.

[7] Mavlanova, T., Benbunan-Fich, R., \& Koufaris, M. (2012). Signaling theory and information asymmetry in online commerce. Information \& Management, 49(5), pp. 240-247.

[8] Feldman, Jack M., \& John G. Lynch, JR. (1988). SelfGenerated Validity and Other Effects of Measurement on Belief, Attitude, Intention, and Behavior. Journal of Applied Psychology, 73, 421 435.

[9] Han Kwang Seok. (2011). The Effect on Accessibility and a Diagnosticity by the Message Type of the Online Review. Advertising Research, (88), 273-304

[10] Choi Beom Joon, Song Mee Ryoung., \& Chu Wu Jin. (2002) The Effects of Use of Infomediary and Brand on On - line Consumer`s Purchase Intention. Korea Consumer Association. 13(2), 187-206

[11] Jin Lian Hua., \& Sohn Sung Kyu. (2009). Research on Overall Disclosure Quality. Korea Accounting Information Association, 27(2), 145-175.

[12] Crosby, L. A., Evans, K. R., \& Cowles, D. (1990). Relationship quality in service selling: An interpersonal influence perspective. Journal of Marketing, 54, 68-81.

[13] Choi Kyu-Hwan, \& Yeo Ho-Kuen. (2009). A Study on the Tourists Decision Making in Tourism Information Asymmetry Situation. Journal of Tourism and Leisure Research, 21(2), 7-26.

[14] Schwarz, Nobert. (1990). Feelings as information: Informational and motivational functions of affective states," In E. T. Higgins \& R.M. Sorrentino (Eds.), Handbook of motivation and cognition: Foundations of social behavior (Vol. 2, pp. 527-561). New York: Guilford.72, 311-329.

[15] Bohner, G., Crow, K., Erb, H. P., \& Schwarz, N. (1992). Affect and persuasion: Mood effects on the processing of message content and context cues and on subsequent behaviour. European Journal of Social Psychology, 22(6), 511-530.

[16] Lim Seung Lark., \& Kim Ji Hae. (2001). SOM(State of Mind) Model for Emotional Judgement: Asymmetry between Positive and Negative Information. Korea Society for Emotion and Sensibility, 4(2), 69-77.

[17] Lee Jong Sil., \& Lim Chae Kwan. (2005). The Effect of Hotel Information System Quality on Information System Performance. International Journal of Tourism and Hospitality Research, 19(2), 189-203.

[18] Park JH. (2000). Medical marketing. Ith ed. Hong Pub, Seoul, 51-62,

[19] Lee Hyoung Tark., \& Lim Young Bean. (2007). Articles: The Relative Efficacy of Trust Dimensions in Forming Overall Customer Trust towards the Service Provider. Korean Society Of Consumer Studies, 18(1), 195-224.

[20] Oh Jae-sin, Kang Tae-gyung., \& Heo Mi-ok. (2010). The Influence of Quantity of Reviews on WOM Acceptance and WOM Intention: Focused on Moderate Effect of Knowledge and Involvement. The Journal of Internet Electronic Commerce Resarch, 10(1), 81-103.

[21] Chu Wu Jin., \& Roh Min Jung. (2009). The Effect of Number, Distribution, and Skewness of Peer Reviews on 
Hedonic and Utilitarian Consumption. Korean Journal of Marketing, 24(1), 109-143.

[22] Hwang In Suk. (2011). Effects of Word-of-Mouth on Consequences of City Marketing. Korea Consumer Associatin, 22(1), 199-217.

[23] Ahn Joo-Ah. (2008). Perceived Risk of Internet Shopping Mall Brand Consumers According to Purchasing Experience and the Effect of Perceived Risk on Information Search and Purchasing Intention. Journal of Communication Science, 8(1), 161-194.

[24] Han Kwang-hee, Ryu Yong-joon, Kim Tae-soon., \& Heo Jun-haeng. (2010). Input Variables Selection of Artificial Neural Network Using Mutual Information. Journal of Korea Water Resources Association, 43(1), 81-94.

[25] King, W. R., \& Epstein, B. J. (1983). Assessing Information Systems Value. Decision Sciences, 14(1), 34-45.

[26] Corbitt, B. J., T. Thanasankita., \& H. Yi (2003), Trust and ecommerce: A study ofconsumer perceptions," Electronic Commerce Research and Applications, (3), 203-215.

[27] Delone, W. H., \& McLean, E. R. (2003). The DeLone and McLean model of information systems success: a ten-year update. Journal of management information systems, 19(4), 9-30.

[28] Kim Doo-Gyung, Jang Sung-Soo, Kang Jae-Eun. (2006). The Research on Evaluating the Quality for an Website of Providing Tourism Information. Journal of Tourism and Leisure Research, 18(3), 311-325.

[29] Hong, Hee-Sook., \& Jin, In-Kyung. (2011). An Exploratory Study of Important Information on Consumer Reviews in Internet Shopping. The Korea Society of Clothing and Textiles, 35(7), 761-774.

[30] Kim So Hyun. (2013). Online Product Word-of-Mouth is Information Whether Persuade Knowledge or Valuable for Consumers -The Moderation of Regulatory Focus on Customer Purchase Intention. Advertising Research, (96), 7 46.

[31] Maheswaran, Durairaj., \& Joan Meyers-Levy. (1990), The Influence of Message Framing and Issue Involvement. Journal of Marketing Research, 27, 3 (Aug), 361-367.

[32] Levin, I. P., Schneider, S. L., \& Gaeth, G. J. (1998). All frames are not created equal: A typology and critical analysis of framing effects. Organizational behavior and human decision processes, 76(2), 149-188.

[33] Kim Ji-Young., \& Yoon Youngmin. (2010). The Effects of Online Comments on Perceived Usefulness and Credibility of Online Consumer Reviews. Korean Journal of Broadcasting and Telecommunication Studies, 24(1), 7-45.

[34] Kemmelmeier, Markus. (2004). Separating the Wheat From the Chaff: Does Discriminating Between Diagnostic and Nondiagnostic Information Eliminate the Dilution Effect? Journal of Behavioral Decision Making, 17, 3, 231-243.

[35] Lee Thae Min, Park Cheol. (2006). Effects of Direction and Type of Electronic Word of Mouth Information on Purchase Decision: Cross-Cultural Comparison between Korea and U. S. Korean Journal of Marketing, 21(1), 29-56.

[36] Han, Kwang Seok., \& Lee, Chong Min. (2009). A Study of the effects of Four Types of Memory-Based Advertising Information on memory Accessibility-Diagnosticity. THE KOREAN JOURNAL OF ADVERTISING, 20(6), 55-81.

[37] Reed, A. E., Chen, L., \& Mikels, J. A. (2014). Meta-analysis of the age-related positivity effect: age differences in preferences for positive over negative information. Psychology and Aging, 29(1), 1-15.

[38] Nam Mi-Kyung., \& Bang Hee-Jeong. (2018). Positivity Effect in Selective Attention and Memory Retrieval of Emotional Information among Older Adults. THE KOREAN JOURNAL OF DEVELOPMENTAL PSYCHOLOGY, 31(4), 99-122.

[39] Chevalier, J. A., \& Mayzlin, D. (2006). The effect of word of mouth on sales: Online book reviews. Journal of marketing research, 43(3), 345-354.

[40] Kim, Woo-Hyuk. (2017). The Impact of Online Reviews on Customer Satisfaction: An Application of the American
Customer Satisfaction Index (ACSI). International Journal of Tourism Management and Sciences, 32(5). 65-78.

[41] Kim Bong Joon., \& Hwang Ui-Rok. (2007). The Effect of Product Evaluation Information on the Consumer Decision Making in the On-Line Context - The Word of Mouth Effect of Product Review and Consumer Replies. Korean Academic Society Of Business Administration, 1-27.

[42] Cho, Sin-Hee · Yi., \& Mun Yong. (2014). Business Implications of the Factors that Determine Online Review Helpfulness. Entrue Journal of information Technology, 13, 29-40.

[43] Son kyungwon. (2010). A Study on the Directions and Tasks of Moral Education Based on Individual Differences of Social and Emotional Skill. Journal of Moral \& Ethics Education, (31), 257-292.

[44] Meyerowitz, Beth E., \& Shelly Chaiken. (1987). The effect of message framing on breast self-examination attitudes, intentions, and behavior. Journal of Personality and Social Psychology, 52(3), 500-510.

[45] Fiske, S. T., \& Taylor, S. E. (1991). Social cognition. Mcgraw-Hill Book Company.

[46] Mizerski, R. W. (1982). An attribution explanation of the disproportionate influence of unfavorable information. Journal of Consumer Research, 9(3), 301-310.

[47] Richins, M. L. (1983). Negative word-of-mouth by dissatisfied consumers: A pilot study. Journal of marketing, 47(1), 68-78

[48] Berger J , Sorensen AT., \& R asmussen SJ. (2010). Positive Effects of Negative Publicity: When Negative R eviews Increase Sales. Marketing Science Electronic Publishing, 29(5), 815-827

[49] Longpré, L., \& Mocas, S. (1993). Symmetry of information and one-way functions. Information Processing Letters, 46(2), 95-100.

[50] Mulhern, F. (2009). Integrated marketing Communications: From Media Channels to Digital Connectivity. Journal of Marketing Communications, 15(2-3), 85-101.

[51] Boyd, D. M. \& Ellison, N. B. (2007). Social Network sites: Definition, History, \& Scholarship. Journal of Computer Mediated Communications, 13, 210-233.

[52] Luck, E. \& Moffait, J. (2009). IMC: anything really changed? A new perspective on an old definition. Journal of Marketing Communications, 15(5), 311-325.

[53] Schultz, D., \& H. Schultz. (1998). Transforming marketing communication into the twenty-first century. Journal of Marketing Communications, 4(1), 9-26.

[54] Lee Chong-Min., \& Kim You-Kyung. (1999). The Relative Roles of Brand Belief and Attitude Toward the Ad in the Formation of Brand Attitude - Considerations Across Product Involvement and Expert Knowledge Levels. Korean Journal of Journalism \& Communication Studies, 44(1), 328-370.

[55] Ki, H. M., \& Lee, Y. R. (2006). Effect of atmospheric music and advertising photo on consumers' emotional state and approach behavior in fashion store. Journal of Global Academy of Marketing Science, 16(3), 39-60.

[56] Park, D., J. Lee, \& Han, I. (2007). The Effect of On-Line Consumer Reviews on Consumer Purchasing Intention: The Moderating Role of Involvement. International Journal of Electronic Commerce, 11(4), 125-148.

[57] Baker, William E., \& Richard J. Lutz. (1987). The Relevance-Accessibility Model of Advertising Effectiveness, in Nonverbal Communications in Advertising. SidneyHecker and David W. Stewart, eds. Lexington, MA: Lexington Books.

[58] Keller, Kevin Lane. (1991). Cue Compatibility and Framing in Advertising. The Journal of Marketing Research, 28(1), 42)57.

[59] Baik, I. S. (2007). The effect of the social comparison against appearance management working people's appearance information conjugate appearance management 
and fashion product purchases. Jooang University-Phd Dissertation.

[60] Lim Tae Kyun, Shin Hyun Geol, Jeong Seok Woo. (2011). Effect of K-IFRS on the Information of Timely Disclosure. Korean management review, 40(2), 297-323.

[61] Moon, Y. J. (2013). The Effect of Perceived e-Service Quality and Other-Word of Mouth on Customer Satisfaction and Revisit Intention-In a Family Restaurant Website. Journal of the Korea Academia-Industrial cooperation Society, 14(5), 2157-2167.

[62] Isen, Alice M., Aparna A. Labroo. (2003). Some Ways in Which Positive Affect Facilitates Decision Making and Judgment. in Emerging Perspectives on Decision Research, ed. Sandra L. Schneider and James R. Shanteau, New York: Cambridge, 365-93.

[63] Chul Ha, Kang. (2018). The Legal System with Regard to the Protection of Personal Data in Korea and Implications for Improvement. Ewha Legal Science Institute, 22(3), 163-199.

[64] Sohn Hae Kyung., \& Yoon Yoo Shik. (2012). The effect of emotional state of post-impulse buying on shopping rebehaviour: Focused on the moderating effect of self-esteem and sensation seeking. International Journal of Tourism and Hospitality Research, 26(6), 117-136.

[65] Negash, S., Terry, R., \& Igbaria, M. (2003). Quality and effectiveness in web-based customer support systems. Information and Management, 40(8), 757-768.

[66] Esposito Vinzi, V., Chin, W. W., Heneseler, J., \& Wang, H. (2010). Handbook of partial least squares: Concepts, methods, and applications. New York, NY: Springer.

[67] Liu, C. (2020). A Study on the Impact of Knowledge Management on Supplier Orientation in Sustainable Supply chains. INTERNATIONAL JOURNAL OF EMERGING MULTIDISCIPLINARY RESEARCH (IJEMR), 5(1), 21-27.

[68] Park, S. T., \& Oh, M. R. (2019). An empirical study on the influential factors affecting continuous usage of mobile cloud service. Cluster Computing, 22(1), 1873-1887.

[69] Li, G., Park, E. M., \& Park, S. T. (2016). Effects of social media usage on country image and purchase intention from social P2P network perspective. Peer-to-Peer Networking and Applications, 9(3), 487-497.

[70] Park, E.M., \& Seo, J.H. (2021). A Study on Factors Influencing Corporate Patent Activities on Management Performance . Journal of the Korea Convergence Society, 12(2), 271-277.

[71] Wetzels, M., Odekerken-Schröder, G., \& Van Oppen, C. (2009). Using PLS path modeling for assessing hierarchical construct models: Guidelines and empirical illustration", MIS quarterly, 177-195.

[72] Fornell, C., \& Larcker, D. (1981). Evaluating Structural Equation Models with Unobservable Variables and Measurement Error", Journal of Marketing Research, 18(1), 39-50.

[73] Gefen, D., \& Straub, D. (2005). A practical guide to factorial validity using PLS-Graph: Tutorial and annotated example. Communications of the Association for Information systems, 16(1), 5 . 